\title{
Can exit prizes induce lame ducks to shirk less? Experimental evidence.*
}

\author{
Leif Helland ${ }^{\dagger} \quad$ Jon Hovi $^{\ddagger} \quad$ Lars C Monkerud ${ }^{\S}$
}

February 10, 2011

\begin{abstract}
Elected representatives serving their final period face only weak incentives to provide costly effort. However, overlapping generations (OLG) models suggest that exit prizes sustained by trigger strategies can induce representatives in their final period to provide such effort. We evaluate this hypothesis using a simple OLG public good experiment, the central treatment being whether exit prizes are permitted. We find that a significantly higher number of subjects in their final period contribute when exit prizes are permitted. However, this result does not originate from use of trigger strategies. More likely explanations include gift-exchange and focal-point effects.
\end{abstract}

${ }^{*}$ The University of Oslo, Department of Political Science, generously funded this project. We are thankful for comments from participants at the ECPR general conference (Potsdam, september 09), and the 4th Nordic Conference in Behavioral and Experimental Economics (Oslo November 09).

${ }^{\dagger}$ Department of Economics, BI Norwegian School of Management

‡Department of Political Science, University of Oslo

$\S$ Department of Economics, BI Norwegian School of Management 


\section{Introduction}

Legislative parties comprise overlapping generations of elected representatives. Having finite biological and political lives, representatives eventually reach their final legislative period. When a representative realizes that she has reached her final period, she becomes a lame duck. ${ }^{1}$ Reelection concerns can then no longer discipline her actions. This creates a tension; while a party's remaining (and future) representatives derive benefits from continued effort by lame ducks, a lame duck motivated by self interest will decline to provide costly effort unless she is incentivized to do so.

Whereas only few studies have focused on final-period behavior in assemblies outside the United States, ${ }^{2}$ a voluminous body of research has considered final-period behavior in the US Congress. ${ }^{3}$ These US studies have provided mixed results that to some extent contradict predictions derived from agency models. In particular, most studies have found some degree of final-period attendance shirking, but only scant evidence of deviant voting (ideological shirking). Scholars often ascribe the latter finding to selection bias; only candidates with preferences akin to those of their constituencies will likely be elected. It is less clear why constituencies apparently do not select representatives that also continue to attend in their final period (Rothenberg and Sanders 2000). The choice of operational definitions impact on findings and may help explain the mixed results. Among other things, scholars differ over questions such as how ideological deviations should be measured and when the final period begins.

This study serves a three-fold purpose. First, few previous studies have considered the important question of how political parties might use attractive retreat positions and other post-office perks to influence final-period behavior.

\footnotetext{
${ }^{1}$ We use the term "lame duck" liberally; meaning representatives that know they are in their "final period". In a strict sense the term lame duck characterizes a representative in the time between electoral defeat and exit from the legislature. In the US Congress lame duck periods are fairly short; lasting from the announcement of electoral loss until replacement by a winner a few weeks later. In parliamentary systems lame duck periods may last considerably longer: from a representative is denied re-nomination prior to election until replacement takes place several months later. Of course, a representative might be in her last period without recognizing this: for example due to sudden and unexpected death or electoral defeat. In such cases she is not a lame duck, and does not face special incentives problems. Since we use an experimental setup in which reelection is exogenously given, lame duck periods unambigously corresponds to final periods.

${ }^{2}$ Notable exceptions include Besley's and Larcinese's (2011) study of attendance shirking in the British parliament, as well as Lien's (2008) study of attendance shirking in the Norwegian parliament.

${ }^{3}$ Bender and Lott (1996) provide a critical review of the field. Lott (1990) deals explicitly with post-elective office employment. More recent contributions include Rothenberg and Sanders (2000), Parker and Powers (2002) and Parker (2004).
} 
We contribute towards filling this gap. Second, we do so by using a novel experimental approach. We believe that the study of final-period behavior can profit from experimental control, because such control allows for explicit regulation of rewards, containment of reputational concerns to the legislative game, unambiguous separation of the final period from preceding periods, and elimination of selection bias. Our approach is novel in that it uses automatons to mimic an indefinite time horizon in the laboratory. Finally, underlying many previous studies of final-period behavior is Alchian's and Demetz's (1972) framework (cf. Crain, Leavens and Tollison 1986), which treats incentive schemes as exogenously given. Taking the common view that control of procedures and institutions constitutes a defining characteristic of majority assemblies, this is clearly unsatisfactory (Krehbiel 1990, Shepsle 1986). Our experimental design allows incentive schemes to be determined endogenously through majority choice.

We demonstrate that in the public goods OLG model, (sufficiently large) exit prizes supported by trigger strategies can sustain a fully cooperative equilibrium in which even lame ducks contribute. ${ }^{4}$ Absent exit prizes, no equilibrium exists in which lame ducks contribute. However, partially cooperative equilibria, in which all remaining representatives contribute, may still exist (Shepsle and Nalebuff 1990, Cremer 1992, Hammond 1975). With or without exit prizes, other equilibria also exist. In particular, playing the stage-game equilibrium (in which no player contributes) in every period is always an equilibrium. ${ }^{5}$ To fix ideas, one may think of exit prizes as attractive retreat positions. ${ }^{6}$ Political parties commonly award such positions to retired top politicians. ${ }^{7}$

\footnotetext{
${ }^{4}$ Salant (1991:255) suggests, but does not analyze, the effect of exit prizes in the generic two-player public goods OLG game. Exit prizes in a purely distributive OLG game are analyzed in Alesina \& Spear (1988). In their model electoral competition is endogenous. There is a growing literature on the distribution of agenda setter rights and other valuable positions in legislative assemblies with overlapping generations of legislators (Muthoo and Shepsle 2007, 2004; Shepsle, Dickson and Houweling 2002; Diermeir 1995). The incentive schemes considered in this literature deviate slightly from ours, in that members gradually obtain more valuable positions in equilibrium (a "seniority system"). In these models (as in ours) electoral competition is exogenous. The impact of exit prizes is not considered.

${ }^{5}$ Kandori 1992 characterizes folk theorems for OLG games with varying information about the history of the game.

${ }^{6}$ Examples include a position as director or board member of a public company, an ambassador post, a leading position in national or sub-national administration. Related options include campaign support (financing and endorsement) for a top international position.

${ }^{7}$ Political scientists debate whether attractive retreat positions serve primarily as rewards for services rendered, or as instruments for cementing partisan power in the longer run, refered to as "patronage" (see for instance Pappas 2009; and Kopecký and Scherlis 2008, with references). We do not see a fundamental conflict here. As long as attractive retreat positions remain scarce, party leaders can use them both to discipline current legislators and to entrench power in the longer run. And even if such positions were to be used mainly for long-run entrenchment, party leaders selecting among otherwise comparable candidates
} 
We examine the impact of exit prizes in a simple OLG experiment. Our treatment is whether exit prizes are permitted. We treat electoral support as exogenously given, and representatives are reelected a fixed number of times. ${ }^{8}$ In each period subjects choose individually and simultaneously whether to contribute to the provision of a public good. We may think of such contributions as costly effort needed for the production of constituency services. ${ }^{9}$ As a simplifying assumption we let the quantity of the public good increase linearly in the number of contributions. Monetary payoffs reflect the assumption that representatives value the public good, but dislike effort. By design, the exit prize offsets the cost of contributing for the lame duck, while it is cost free for remaining subjects to award the prize. ${ }^{10}$

Few previous experiments addressing the ability of trigger strategies to support high contribution levels in an OLG public-goods game have been carried out. Notable exceptions include Van der Heijden et al. (1998) and Offerman and Verbon (2001). Both of these experiments consider a game with two players per period, in which only the newborn player takes an action. In contrast, we consider a strategically richer OLG game with three players per period, all of whom take actions. In keeping with the two mentioned studies, the subjects in our experiment face a binary choice (contribute vs. not contribute). Van der Heijden et al. (1998) study the impact of the game's information structure on contribution levels and on the variability of contributions. They find that knowledge of the game's history explains neither the level of contributions nor their variability. Offerman and Verbon (2001) consider the impact of recommending the use of a trigger strategy. They find that such a recommendation increases the contribution level and causes many subjects to use trigger-like strategies. However, because of a remaining group of unconditional defectors,

should avoid candidates with a history of shirking.

${ }^{8}$ This is clearly a simplifying assumption. It may well be that behavior would change in the experiment if reelection was endogenous (and linked to individual contributions or aggregate production). Exogenous reelection allow us to focus more clearly on our main question; can exit prizes incentivize lame ducks.

${ }^{9}$ Shepsle and Naelbuff (1990) provide an alternative interpretation, in which aggregate efforts produce "power".

${ }^{10}$ We have resisted the temptation to motivate our experiment more broadly, say, by refering to a richer array of organizations with end-period challenges. In most organizations awarding a bonus for good behavior entails costs for the remaining players. Legislatures are special in this regard. Remaining legislators are not competing for the positions (= bonuses) concerned, so they do not incur a direct cost by awarding such a position to an outgoing representative. In addition, awarding a position to an outgoing representative (rather than to an outside competitor) entails only modest audience costs. Retired legislators will likely be as competent as outside competitors for such positions. Furthermore, the positions in question are usually long term, so current legislators will unlikely compete for them in the near future. 
the fully cooperative outcome fails to materialize.

Scholars continue to discuss how one might best mimic an indefinite horizon in OLG experiments. Van der Heijden et al. (1998) use a fixed and publicly known last period. Because of this the cooperative outcome cannot be sustained as an equilibrium, which implies serious problems for studying the impact of trigger strategies. Offerman and Verbon (2001) let subjects play a single OLG game ("no reincarnation") with a constant and publicly known periodic stopprobability. As they note, with this procedure the number of subjects in the lab imposes a publicly known upper bound on the number of periods in the game. Therefore, the game is not indefinitely repeated in a proper sense. OLG experiments conducted in the context of monetary economics rely on a third approach (Lim et al. 1994, Marimon and Sunder 1993), where subjects enter repeatedly in a longer game ("reincarnation"). The reincarnation approach entails that the experimental game becomes much more complicated than the OLG models that motivated it (OLG models do not admit "reincarnation").

We use a novel design in which automatons replace one subject in the penultimate period and two subjects in the ultimate period of a five-period game (see table 1). The automatons are programmed to follow a trigger strategy. This design solves several problems encountered in previous OLG experiments. It also reduces the set of equilibria - an attractive feature for our purposes. The reader might object that the automatons provide a powerful focal point (Schelling 1960) that will likely impact on behavior. Our response is two-fold. First, previous research shows that providing a focal point in the form of a strategy recommendation fails to bring out clear trigger-like behavior in OLG public-goods experiments, and our own results suggest that the (even stronger) focal point provided by our automatons also fails to generate trigger-like behavior. Second, while no-one has thus far come up with a procedure capable of perfectly mimicking an indefinite horizon in OLG experiments, our automatons provide a nice and novel way of circumventing this serious problem. We describe our automatons in detail in the section on experimental design.

Our research question is: Do exit prizes induce lame ducks to contribute to the public good? We find that a significantly higher number of outgoing subjects contribute in the treatment with exit prizes than in the treatment without exit prizes. However, we show that this result does not derive from the use of trigger strategies.

The next section depicts the OLG public-good model underlying our experiment. The third section outlines our experimental design. The fourth section 
contains descriptive statistics. The fifth section presents the main results. The sixth section concludes.

\section{Model}

Consider a $T$-person overlapping generations game under the standard assumptions of self-regarding and rational players. Each period corresponds to a stage game with Prisoners Dilemma (PD) payoffs, in which $n=3$ players move simultaneously. Information is complete and (almost) perfect. ${ }^{11}$ It is common knowledge that the game ends in period $T$. The stage game in period $T$ is played by two automatons and a human; the stage game in period $T-1$ is played by two humans and an automaton. In periods $t=1,2, \ldots, T-2$ the stage game is played by three humans. A player is either in position $A, B$ or $C$. The player in $A$ plays her first stage game, the player in $B$ plays her second to last stage game, while the player in $C$ plays her last stage game. The automaton in $T-1$ plays in position $A$, while the automatons in period $T$ plays in positions $A$ and $B$ respectively.

\section{No prize}

The material payoff of player $i$ in stage game $t$ is

$$
v_{i, t}=z\left(1-d_{i, t}\right)+\beta \sum_{j=1}^{n} d_{j, t} z
$$

In equation (1) $z>0$ denotes player $i$ 's (exogenously given) endowment (players are assumed to have identical endowments). $d_{i, t}$ is a dummy that takes the value 1 if $i$ contributes to the public good in stage $t$, and 0 otherwise. A $\mathrm{PD}$ structure on material payoffs requires $\frac{1}{n}<\beta<1$. Since $\beta<1, d_{i, t}=0$ is a dominant strategy in the stage game. The unique stage game equilibrium is $d_{i, t}=0 \forall i \in T$. Since $\beta>\frac{1}{n}, d_{i, t}=1 \forall i \in T$ Pareto-dominates the stage game equilibrium.

Let the state $R_{t}$ be: $d_{i, t^{\prime}}=1$ for $i=(A, B)$ in all periods $t^{\prime}<t$. A "grim trigger" for the game can now be defined as follows: set $d_{i, t}=1$ if in $A$ or $B$

\footnotetext{
${ }^{11}$ The "almost" implies that the history up to period $t$, but not including period $t$, is common knowledge.
} 
and state is $R_{t}$, otherwise set $d_{i, t}=0$. The automatons used in the no prize treatment were programmed to follow this grim trigger.

On the equilibrium path of the grim trigger, a player in $A$ nets $(6 \beta+1) z$; a player in $B$ nets $(4 \beta+1) z$; and a player in $C$ nets $(2 \beta+1) z$. By a single deviation the player in $A$ nets $(\beta+3) z$; the player in $B$ nets $(\beta+2) z$; while the player in $C$ nets $3 \beta z$. It follows that the player in $A$ cannot profit by a single deviation from the equilibrium path of the grim trigger (by not contributing) if $\beta \geq \frac{2}{5}$. Similarly, the player in $B$ cannot profit by such a deviation if $\beta \geq \frac{1}{3}$. Finally, the player in $C$ cannot profit by deviating from the equilibrium path (by contributing) if $\beta<1$.

Once the punishment path has been triggered, no player can profit by a single deviation from this path, since such a deviation would only reduce her payoff by $(1-\beta) z$. It follows that grim trigger is subgame perfect if $\beta \geq \frac{1}{3}$.

Given the way the automatons are programmed, only one other equilibrium exists. In this equilibrium all players set $d_{i, t}=0$.

\section{Prize}

Consider now the game with exit prizes. This game differs from the previous game in one respect only. After the players have taken their contribution decisions and these decisions have been announced, players in positions $A$ and $B$ vote on whether to award a prize $\theta z$, with $\theta>0$, to the player in position $C$. The prize is only awarded if both of the players vote "yes". The material payoff to players in positions $A$ and $B$ is identical to the one described in equation (1). The material payoff to the player in position $C$ is:

$$
w_{i, t}=v_{i, t}+e_{t} \theta z
$$

In equation (2) $e_{t}$ is a dummy that indexes the outcome of the vote in stage game $t$. $e_{t}$ takes the value 1 if both of the players in $A$ and $B$ vote "yes", and 0 otherwise. Let state $S_{t}$ be: $d_{i, t^{\prime}}=1$ for $i=(A, B, C)$ and $e_{t^{\prime}}=1$, in all periods $t^{\prime}<t$. A grim trigger for the game with prize is defined as follows: If (a) in state $S_{t}$ set $d_{i, t}=1$; (b) in state $S_{t}$, in position $A$ or $B$, and $d_{i, t+1}=1$ for $i=(A, B, C)$, vote "yes". Otherwise set $d_{i, t}=0$ and do not vote "yes". In our experiment, the automatons of the game with prize were programmed to follow this grim trigger. 
On the equilibrium path of the grim trigger the player in position $A$ nets $(9 \beta+\theta) z$; the player in $B$ nets $(6 \beta+\theta) z$; while the player in $C$ nets $(3 \beta+\theta) z$. Consider first a single deviation $d_{i, t}=0$ from the equilibrium path of the grim trigger. Such a deviation nets $(2 \beta+1) z$ for the player in $C$; it nets $(2 \beta+2) z$ for the player in $B$; and it nets $(2 \beta+3) z$ for the player in $A$. So, the player in $C$ has no incentive to perform such a deviation if $\beta \geq(1-\theta)$, the player in $B$ has no incentive to perform such a deviation if $\beta \geq\left(\frac{2-\theta}{4}\right)$, while the player in $A$ has no incentive to perform such a deviation if $\beta \geq\left(\frac{3-\theta}{7}\right)$. If $\theta \leq \frac{2}{3}$ then $(1-\theta) \geq\left(\frac{2-\theta}{4}\right) \geq\left(\frac{3-\theta}{7}\right)$. This means that if $\theta \leq \frac{2}{3}$ and the player in position $C$ has no incentive to perform a single deviation by playing not contribute, then neither have players in positions $B$ or $A$ an incentive to do so.

Next, consider the possibility of a single deviation from the equilibrium path of the grim trigger consisting of players $A$ or $B$ voting "no" to awarding the prize. By voting "no" a player in $B$ nets $z$, which is clearly less than what he nets if he deviates by setting $d_{i, t}=0$. By voting "no" a player in $A$ nets $2 z$ which is clearly less than what he nets if he deviates by setting $d_{i, t^{\prime}}=0$. Thus, players in positions $A$ and $B$ (who have a choice as to what kind of deviation to perform), will never deviate by voting "no" while continuing to contribute.

Finally, consider a single deviation from the punishment path of grim trigger, consisting of $d_{i, t}=1$. A player in position $C$ nets $\beta z$ by performing such a deviation, while he nets $z$ if he abstains. A player in position $B$ nets $(\beta+1) z$ by performing such a deviation, while he nets $2 z$ if he abstains. Lastly a player in position $A$ nets $(\beta+2) z$ by performing such a deviation, while he nets $3 z$ if he abstains. Clearly, no player has an incentive to perform a deviation from the punishment path of grim trigger by setting $d_{i, t^{\prime}}=1$.

The remaining question is whether players in position $A$ or $B$ can profit by deviating from the punishment path of the grim trigger by voting "yes". The answer is clearly no. One "yes" is not sufficient to change the outcome from no-prize to prize, so the deviation cannot be profitable. Since voting is cost free players in $A$ and $B$ do not have a strict incentive to coordinate on a "no" vote. On the other hand, neither do they have a strict incentive to coordinate on a "yes" vote.

Summing up, in the prize treatment the grim trigger is sub-game perfect if $\theta \leq \frac{2}{3}$ and $\beta \geq(1-\theta)$. Given the way the automatons are programmed, there is only one other subgame-perfect equilibrium. In this equilibrium players in positions $A, B$ and $C$ always set $d_{i, t}=0$ and never vote "yes". 


\section{Design}

Our experimental design had $T=5, n=3, z=100$ and $\beta=0.6$. This applied both to the treatment with prize and to the treatment without prize. In the treatment with prize, $\theta=0.5$. We specified payoffs in an "experimental currency" called schillings. Every contribution (whether made by a subject or by an automaton) increased the sum of payoffs by 180 schillings, which were distributed equally among the three subjects who were active players in that period (60 schillings per subject), irrespective of the subjects' own decisions. In the prize treatment, lame ducks that were awarded a prize received an additional 50 schillings. We communicated the resulting payoff structure to the subjects via the instructions (available upon request).

We conducted both the prize and the no-prize treatments with three subjects in periods 1, 2 and 3, one automaton and two subjects in period 4, and two automatons and one subject in period 5 (the final period). A game required 5 subjects altogether (cf. table 1). We played four games of the no-prize treatment, and four games of the prize treatment. No subject played more than one game, so this required 40 subjects; 20 subjects in the no-prize treatment, and 20 subjects in the prize treatment. To expand the number of observations, we repeated this basic design with 40 additional subjects. The required 80 subjects were recruited (by e-mail) from undergraduate classes at BI Norwegian School of Management. Since our lab has a capacity of 20 subjects we conducted four sessions, two with the no-prize treatment, and two with the prize treatment. ${ }^{12}$

\begin{tabular}{llll}
\hline \hline & Position $A$ & Position $B$ & Position $C$ \\
\hline Period 1 & Subject $I I I$ & Subject $I I$ & Subject $I$ \\
\hline Period 2 & Subject $I V$ & Subject $I I I$ & Subject $I I$ \\
\hline Period 3 & Subject $V$ & Subject $I V$ & Subject $I I I$ \\
\hline Period 4 & Automaton & Subject $V$ & Subject $I V$ \\
\hline Period 5 & Automaton & Automaton & Subject $V$ \\
\hline
\end{tabular}

Table 1: Structure of interaction

For each session we invited 24 subjects in total. Whenever more than 20 subjects showed up, we withdrew excess subjects through random draws. A withdrawn subject received a show-up fee of 150 NOK (approximately 23 USD).

\footnotetext{
${ }^{12}$ The experiment was conducted on two separate days. Each day we ran one session without prize and one with prize (in that order).
} 
In contrast, participating subjects received no show-up fee. We randomly distributed the 20 subjects participating in a given session to the four groups. Also, we randomly assigned numbers from $I$ to $V$ to the five subjects in each group. These numbers determined the starting positions of subjects. We communicated the programming of automatons to the subjects through the instructions.

We informed subjects that they would receive their payoffs in cash once their session was over and that schillings would be converted to NOK using the exchange rate 1 schilling $=0.55$ NOK. ${ }^{13}$ Because it was impossible to earn more than NOK 1000 in this experiment, the payoffs were tax free by the tax laws of our country. As there was no show-up fee for participating subjects, their minimum earning was 99 NOK (approximately 15 USD). ${ }^{14}$

During the experiment all interaction took place via a network of computers. ${ }^{15}$ Before starting the experiment, the administrator distributed the instructions and read them aloud (to make them public knowledge). The administrator then asked the subjects several control questions to check that they understood the instructions and the payoff structure. We also conducted a test round (without monetary payoffs) to allow subjects to become familiar with the software. ${ }^{16}$

To compensate for the fact that participants acting as subject $I$ could make a decision in only one period, we offered those participants additional earnings corresponding to twice the average per period payoff in the group. Similarly, because participants acting as subject $I I$ could make a decision in only two periods, we offered these participants additional earnings corresponding to the average per period payoff in the group.

The sessions with prize replicated the sessions without prize, except in the following respect: Once the subjects had taken their contribution decisions, and these decisions were made known to other subjects in their group, the subjects/automatons in positions $A$ and $B$ voted on whether to award the subject in position $C$ a prize of 50 schillings. Awarding the prize required two votes in favor.

\footnotetext{
${ }^{13}$ In order to restrict social pressures, subjects entered a separate room one at a time to collect their earnings.

${ }^{14}$ Given by the (unlikely) event that the subject would be the sole contributor in all three periods.

${ }^{15}$ Programmed on Z-tree (Fischbacher 1999).

${ }^{16}$ After the test round we randomly rematched groups and starting positions, in order to avoid reputation buildning based on test-round behavior.
} 


\section{Descriptive statistics and analytic choices}

In this section we present descriptive statistics for the two types of decisions subjects made during the experiment (contribute vs. not contribute and award prize vs. not award prize). Table 2 shows average percentage of contributions, depending on position ( $A / B$ vs. $C$ ), and treatment (prize vs. no prize). Similarly, table 3 shows average percentage of subjects in positions $A$ or $B$ voting in favor of awarding a prize to the outgoing subject (position $C$ ) in the prize treatment. The numbers are mean levels for contribution decisions (both treatments) and prize decisions (prize treatment), given as total means and as averages over mean levels within subjects and groups respectively.

\begin{tabular}{lllllll}
\hline \hline & \multicolumn{2}{l}{ Decisions } & \multicolumn{2}{l}{ Subjects } & \multicolumn{2}{l}{ Groups } \\
\hline Position & Prize & No prize & Prize & No prize & Prize & No prize \\
\hline A or B & 69.6 & 46.4 & 70.3 & 48.4 & 69.6 & 46.4 \\
& $(56)$ & $(56)$ & $(32)$ & $(32)$ & $(8)$ & $(8)$ \\
\hline C & 75.0 & 15.0 & 75.0 & 15.0 & 75.0 & 15.0 \\
& $(40)$ & $(40)$ & $(40)$ & $(40)$ & $(8)$ & $(8)$ \\
\hline
\end{tabular}

Table 2: Average percentage of contributions, contingent on position $(A / B$ or $C)$ and treatment (prize or no prize). Percentage of decisions, averages over withinsubject decision percentages, averages over within-group decisison percentages $(N)$.

\begin{tabular}{lll}
\hline \hline Decisions & Subjects & Groups \\
\hline 80.4 & 82.8 & 80.4 \\
$(56)$ & $(32)$ & $(8)$ \\
\hline
\end{tabular}

Table 3: Average percentage of votes cast by subjects in position $A$ or $B$ to award the prize to the outgoing subject (position $C$ ) in the prize game $(N)$.

Tables 2 and 3 show little difference between, on the one hand, averages based on within-subject means, and, on the other hand, total averages or averages based on group means (the latter two must necessarily yield identical results). As shown in table 2, our data leave us with a maximum of 56 decisionlevel observations, 40 subject-level observations or 8 group-level observations for contribution decisions within a treatment-position combination. Similarly, table 3 shows that further analysis of subjects' propensity to award a prize can be 
based on a total of 56 decision-level observations, 32 subject-level observations or 8 group-level observations.

We report results for group-level observations, which we believe bring us closest to the requirement of independent observations. First, we expect dependencies to exist across different decisions made by the same subject. In fact, it would be strange if no learning or adjustment took place. Second, we expect dependencies to exist across subjects in the same group, because of strategic interaction and because subjects in a given group acquire information about the behavior of other players in that group. Third, Kruskal-Wallis tests reveal significant across-group differences in contribution levels and voting patterns between subjects operating under the same experimental condition (the same combination of treatment and position). This indicates that within-group dependencies actually exist (tests are available upon request).

We use only non-parametric hypothesis tests: Mann-Whitney U-tests (MWU) and Kruskal Wallis (KW) tests for comparisons among group measures that vary only between groups (e.g. treatment effects and unobserved differences between individual groups); Wilcoxon signed-rank tests (WSR) and Friedman tests for comparisons of group measures that may vary within groups (e.g. differences in contributions between different portions or periods of the game); one-sample location tests (OSL) for comparing certain outcomes with model equilibria. Finally, we use the two-tailed $p<0.10$ as the criterion for a significant effect.

\section{Results}

We organize the discussion in two parts. First, we demonstrate that lame ducks contribute more often in the prize treatment than in the no-prize treatment. Second, we explore possible explanations for this finding.

\section{Do prizes induce lame ducks to contribute?}

Both treatments in our experiment include an equilibrium in which no player contributes. However, only the prize treatment also includes an equilibrium in which players in position $C$ contribute. Thus, our main hypothesis is that the

fraction of position $C$ players that contribute is on average at least as high in the prize treatment as in the no-prize treatment.

Table 2 shows that on average only 15 per cent of the subjects in position $C$ contribute in the no-prize treatment. In contrast, 75 per cent of the subjects 
in position $C$ contribute in the prize treatment. This 60 percent difference over treatments is highly significant in a MWU test $(Z=-3.41, p<0.000)$, and thus supports our main hypothesis. ${ }^{17}$ Also, the average percentage of votes to award the prize to the outgoing subject in the prize game seems quite high in substantive terms $(P=80.4$; see table 3$) .{ }^{18}$

To check the robustness of our finding that the prize treatment boosts contributions from the outgoing subject, we check whether a similar difference over treatments exists for positions $A$ and $B$ as well, and whether the difference for position $C$ is stable across periods. A first and overall test of the former proposition can be conducted by comparing overall contribution levels for positions $A$ and $B$ in the prize treatment and the no-prize treatment, respectively (i.e. the difference between $P=69.6$ and $P=46.4$ in table 2). It turns out that no significant difference exists here (MWU test, $Z=-1: 45, p=0.15$ ). In table 4 we investigate these questions further.

\begin{tabular}{lllllll}
\hline \hline \multicolumn{7}{l}{ Period } \\
\hline Position & Treatment & 1 & 2 & 3 & 4 & 5 \\
\hline A or B & Prize & 81.3 & 68.8 & 75.0 & 37.5 & - \\
& No prize & 62.5 & 43.8 & 43.8 & 25.0 & - \\
\hline C & Prize & 87.5 & 87.5 & 87.5 & 75.0 & 37.5 \\
& No prize & 25.0 & 25.0 & 12.5 & 12.5 & 0.0 \\
\hline
\end{tabular}

Table 4: Average number of contributions, contingent on position, treatment and period. $N=8$ for each entry.

Table 4 shows that in periods 1 through 3 , across-treatment differences for subjects in position $C$ are 2 to 3 times larger than the corresponding differences for subjects in positions $A$ or $B$. In period 4 the across-treatment difference for subjects in position $C$ is a sizeable 5 times larger than the corresponding difference for subjects in positions $A$ or $B$. In the final period no subject in position $C$ contributes in the no-prize treatment, whereas almost 40 per cent contribute in the prize treatment. The pattern of gradually diminishing contributions over time that is revealed in table 4 , resembles that observed in non-overlapping

\footnotetext{
${ }^{17}$ However, all four percentages in the rightmost column of table 2 are significantly off the mark in relation to any possible equilibrium outcome: OSL tests for $\mathrm{H} 0: \mathrm{P}=0$ and $\mathrm{H} 0$ : $\mathrm{P}$ $=100$ for the prize- $\mathrm{AB}$, prize- $\mathrm{C}$ and no-prize- $\mathrm{AB}$ conditions and $\mathrm{H} 0: \mathrm{P}=0$ test for the no-prize-C condition all generate p-values less than 0.10 .

${ }^{18}$ Invoking the harsher criterion that data should conform not only to a model's directional predictions but also to its point predictions, we note that this percentage is signifcantly off the mark in relation to both of the model's equilibrium outcomes (specifically, OSL tests of $\mathrm{H} 0: \mathrm{P}=0$ and $\mathrm{H} 0: \mathrm{P}=100$ both produce $\mathrm{p}=0.01$ ).
} 


\begin{tabular}{lllllll}
\hline \hline & \multicolumn{3}{c}{ Period } & & & \\
\hline Position & & 1 & 2 & 3 & 4 & 5 \\
\hline A or B & Z-value & -1.47 & -1.17 & -1.83 & -0.45 & - \\
& p-value & 0.14 & 0.24 & 0.07 & 0.65 & - \\
\hline C & Z-value & -2.38 & -2.38 & -2.84 & -2.38 & -1.78 \\
& p-value & 0.02 & 0.02 & 0.00 & 0.02 & 0.07 \\
\hline
\end{tabular}

Table 5: Mann-Whitney U tests for differences over treatments implied by table 4. Total $N=16$ for each test.

public goods games (without punishments). It is generally thought that such patterns are due to heterogeneity in social preferences. ${ }^{19}$

Table 5 displays MWU tests of the across-treatment differences in contribution levels, conditioned on positions and periods. Whereas a significant difference across treatments exists for the $A / B$ condition in period 3 , all other periodby-period across-treatment differences are non-significant for this condition. In contrast, all period-by-period across-treatment differences are significant for the $C$-position. These results make it evident that the subjects in position $C$ behave differently in the prize and no-prize treatments.

Table 4 also shows a marked tendency for the average number of contributors to decrease over the five periods. Table 6 presents Friedman tests for differences over the five periods. The results suggest that this tendency is significant for all experimental conditions except the $C$ position in the no-prize game, in which contribution levels consistently remain low throughout.

\begin{tabular}{llll}
\hline \hline Position & Treatment & $\chi^{2}$ & p-value \\
\hline A or B & Prize* $^{*}$ & 9.15 & 0.03 \\
& No prize* $^{*}$ & 9.00 & 0.03 \\
\hline C & Prize** & 9.23 & 0.06 \\
& No prize $^{* *}$ & 2.33 & 0.67 \\
\hline
\end{tabular}

Table 6: Friedman tests for differences over periods implied by table 4. ${ }^{*}$ Total $N=32,{ }^{*}$ total $N=40$

That contribution levels decrease over the five periods is not necessarily incompatible with subjects using trigger strategies to sustain cooperation. We now check if subjects stick to the trigger's punishment phase whenever the coop-

\footnotetext{
${ }^{19}$ Ledyard (1995) provides a rich survey of public goods experiments. See for instance Fehr $\&$ Fiscbacher (2002) for more recent work on social preferences in public goods experiments.
} 
erative equilibrium path has been violated. To do this we condition contribution levels on whether the trigger's punishment phase has been activated. When this phase is activated, the trigger instructs subjects to cease contributing and, if relevant, cease voting in favor of awarding a prize for the remainder of the game. Figure 1 conveys a first impression of the results.

\section{Figure 1 here}

The figure displays the evolution of contributions over the five periods, for the 16 groups in the experiment. The two first rows in the figure show play in the eight groups with no prize, whereas the two last rows show play in the eight groups with prize. Hollow circles indicate the sum of contributions for the group (including contributions from the automatons). These are plotted on the left $y$-axis. Black discs, plotted on the right $y$-axis, indicate whether the punishment path of the trigger is activated. The main picture is that contributions tend to fall once the punishment phase is activated, though not instantly (as it should according to theory). While only one group in the no-prize treatment manages to stay on the trigger's equilibrium path for all five periods, two groups manage this in the prize treatment (and one additional group stays on the equilibrium path until the final period). Six groups in the no-prize treatment activate the punishment path by period two, compared to three groups in the prize treatment. In all, prizes clearly delay activation of the punishment path.

Table 7 displays average contribution levels in the two experimental treatments for the part of the game following a deviation from the cooperation path of the trigger strategy, conditioned on position.

\begin{tabular}{lll}
\hline \hline Position & Prize & No prize \\
\hline A or B & 41.3 & 34.3 \\
& $(5)$ & $(7)$ \\
\hline C & 56.9 & 7.1 \\
& $(6)$ & $(7)$ \\
\hline
\end{tabular}

Table 7: Mean contribution levels over treatments in non-cooperative parts of the game, contingent on position $(N)$.

Does the behavioral pattern correspond to what we would expect if subjects were to use trigger strategies? First, OSL tests for all but one of the entries $(P)$ in table 7 (the exception is position $C$ contributions in the no-prize treatment), 
reveal that actual outcomes differ significantly from what one should expect if the trigger had not been activated. Specifically, for these entries tests of $H_{0}$ : $P=100$ (i.e. the cooperative equilibrium outcome of an unbroken trigger) all show $p$-values less than 0.10 , which suggests that activation of the trigger at the very least entails a reduction of contribution levels. These results are consistent with the conjectures provided by game theory. Still, OSL tests of $H_{0}: P=0$ (i.e. the equilibrium outcome once the trigger has been broken) are also consistently significant $(p<0.10)$ for all table entries, save for contributions from the $C$ position in the no-prize treatment $(P=7.1, p=0.50)$. In particular, contribution levels in the prize-treatment $C$ position $(P=56.9)$ are way off the equilibrium mark in substantive terms. ${ }^{20}$

\section{Gift exchange, efficiency and focal point effects}

Why do we observe such a clear breach of equilibrium behavior in our data? In addressing this question we are constrained by our experimental design, and our answers must therefore be suggestive. We focus on three possible explanations. First, by contributing outgoing subjects might be aiming for creating a giftexchange relationship. By contributing, an outgoing subject makes a costly sacrifice for the benefit of the group. The remaining subjects can return this favor - at no cost - by awarding a prize to the outgoing subject. Moreover, this holds regardless of whether the cooperative equilibrium path of the trigger has already been abandoned. Previous research from other settings show that gift exchange may provide a stronger motivation for effort than hard incentives do. ${ }^{21}$ Note that the presence of a gift-exchange relationship would undermine the credibility of the trigger's punishment phase. Second, the high observed rates of "yes" votes and of prizes awarded might reflect efficiency concerns. Specifically, awarding a prize increases the subjects' aggregate monetary payoffs, at no cost to the subjects awarding the prize. There is an ongoing debate in the experimental economics literature regarding the extent to which efficiency concerns impact on

\footnotetext{
${ }^{20}$ Although the p-value is a "mere" 0.06 , this result is most likely influenced by a shortage of observations as some groups (2 out of 8 ) manage to stay on the cooperative path, as well as by the fact that group-level measures become more unstable as aggregates are based on fewer periods/decisions (only those following a switch to the punishment path of the trigger strategy, which, as noted above, tends to come relatively late in the prize treatment).

${ }^{21}$ Gift-exchange relationships have been studied experimentally by Fehr, Gächter and Kirchsteiger (1997), and by Fehr, Kirchsteiger and Reidl (1993, 1998). In Fehr, Klein and Schmidt (2001) the contract design is endogenous (i.e. subjects choose a contract from a menue of available contracts). Fehr and Fischbacher (2005) provide a brief overview of gift-exchange experiments.
} 
behavior. ${ }^{22}$ Finally, across-treatment differences in contribution and "yes-vote" levels may reflect a focal-point effect (Schelling 1960): In addition to introducing an altered strategic environment, the prize treatment arguably creates a strong focus on cooperative behavior as such.

We utilize the comparative static features of our experimental design, first with respect to contributions from the outgoing player and then with respect to "yes-votes". Specifically, our comparisons exploit the fact that subjects' actions (contributions, voting decisions) cannot in any way be decisive for outcomes (awarding the prize) when (1) the trigger's cooperative equilibrium path has been abandoned and (2) automatons have entered the group as players (periods $I V$ and $V)$.

Table 8 lists mean contribution levels for different experimental conditions in which one or two - but not all - of the three mentioned explanations can be operative. If the trigger drives the subjects' behavior, one should observe low contribution levels and little across-treatment differences in cases where the trigger's cooperative equilibrium path has been abandoned. However, the two MWU-tests reported in table 8 show that contribution levels in such cases are in fact significantly higher in the prize treatment (42 to 70) than in the noprize treatment (0 to 17). Moreover, while the results for the upper row in table 8 (i.e. for the early periods of the game) are clearly at odds with trigger behavior, as well as with behavior driven by efficiency concerns, it is consistent with both the gift-exchange hypothesis and the focal-point hypothesis (i.e. the prize treatment creates a "cooperative focus"). In other words, this particular test cannot distinguish between the two latter hypotheses.

\begin{tabular}{lllll}
\hline \hline Periods & Prize & No prize & Z-value & p-value \\
\hline 2 and 3 & 70.0 & 16.7 & 1.86 & 0.06 \\
& $(5)$ & $(6)$ & & \\
\hline 4 and 5 & 41.7 & 0.0 & 2.38 & 0.02 \\
& $(6)$ & $(7)$ & & \\
\hline
\end{tabular}

Table 8: Mean contribution levels for outgoing subjects (position $C$ ) in periods where non-cooperative behavior has occured, by treatment and early and late periods of the game. Z-statistic and p-value for Mann-Whitney U test (N).

\footnotetext{
${ }^{22}$ For a seminal paper dealing with this question in a social preferences framework, see Charness and Rabin (2000). Engelman and Strobel (2002) provide a review and some new experiments, which Fehr, Naef and Schmidt (2005) criticize. Güth, Kliemt and Ockenfels (2000) provide an application dealing directly with public goods provision. Hsu, Anen and Quartz (2008) explore the neurological correlates of equity and efficiency concerns.
} 
Therefore, it makes sense to compare the entries in the bottom row of table 8. Whereas our two treatments differ in more than one respect in early postdefection periods ( $I I$ and $I I I)$, a nice feature of our design is that the treatments do not differ in more than one respect in later periods $(I V$ and $V)$. In our experiment it is public knowledge that automatons will necessarily vote against awarding a prize in periods $I V$ and $V$, assuming that the cooperative equilibrium path has already been abandoned. Hence, it would be pointless to aim at a gift exchange or even engage in any strategic behavior whatsoever in these periods. However, the two experimental treatments differ in the focus they create on cooperation. The substantial and significant difference in contribution levels at this point (42 vs. 0) provides a strong indication of a focal-point effect.

Finally, if the gift-exchange hypothesis is correct, one should expect sharply declining contributions from outgoing subjects as opportunities for gift-exchange behavior wither: The pattern for the player in position $C$ of the prize treatment shown in table 4 is suggestive, with contribution levels decreasing from 87.5 in the first three periods to 50.0 in period $I V$ and 37.5 in period $V$. However, it is not clear to what extent consistently cooperative groups manage to keep the aggregate at relatively high levels. The relevant pattern and test for group aggregates of contributions in situations where the cooperative equilibrium path has been abandoned concern the levels presented in the far left column of table 8. It turns out that a substantial 40 percentage point difference exists in contribution levels between (1) periods where outgoing subjects can be decisive (70) and (2) periods where they cannot be decisive (30, rather than the listed figure of 41.7, which includes a group that cooperates through periods 2 and 3). However, although sizable, this effect is not significant in a WSR test at conventional levels $(S=3.0, p=0.25, N=5) .{ }^{23}$

We now turn to voting patterns in the prize treatment. Table 9 lists the groups-mean of votes cast in favor of awarding a prize to the outgoing player, conditioned upon whether the latter choose to contribute. Table 9 includes only cases where voting occurs after the trigger's cooperative equilibrium path has been abandoned in periods 1,2 or $3 .^{24}$

\footnotetext{
${ }^{23}$ Five groups in the prize treatment have observations both in early periods (II and III) and in late periods (IV and V). In other words, three out of the eight groups are naturally excluded from the analysis: the two groups that manage to stay on the cooperative equilibrium path, and the one group that abandons this path in period IV, so that it plays under the broken trigger only in period $\mathrm{V}$.

${ }^{24}$ We include decisions in period 1 , since the trigger strategy may shift to the punishment path not only as a consequence of non-cooperative play in any previous period, but also as a consequence of any departure from a pattern of across-the-board contributions in the current
} 


\begin{tabular}{lll}
\hline \hline Contribution from C & No contribution from C & Total \\
\hline 0.80 & 0.63 & 0.75 \\
$(5)$ & $(2)$ & $(7)$ \\
\hline
\end{tabular}

Table 9: Mean share of votes in favor of awarding the prize to the outgoing subject (position $C$ ) in periods where non-cooperative behavior has occured before period 4, by contribution from the outgoing player $(N)$.

The overall share of votes cast in favor of awarding a prize after abandoning the cooperative equilibrium path is high $(0.75, N=7)$ and significantly different from zero in a simple OSL test $(p=0.02)$. While at odds with the hypothesis that subjects play trigger strategies, this finding is consistent with the focal-point hypothesis. However, it is also consistent with the gift-exchange hypothesis and the efficiency-concerns hypothesis. While having the right "reciprocal sign" according to the gift-exchange hypothesis, the difference between the contribute condition and the not contribute condition is insignificant. Table 9 shows that only two group-level units have observations in both conditions. The average percentage of "yes-votes" is 0.63 in the not contribute condition, and increases only moderately to 0.80 in the contribute condition for the same two groups. Needless to say, applying the appropriate WSR test with only two group-level units proves futile $(S=0.5, p=1.00) .{ }^{25}$

In essence, our experiment fails to provide statistically strong support for the gift-exchange hypothesis. However, as we explained in our analysis of contribution patterns, it seems that outgoing subjects do not expect a prize to be awarded regardless of whether they contribute. In the prize treatment, subjects usually choose to contribute rather than to keep their endowment hoping that remaining subjects will nevertheless award them a prize (see table 8).

In conclusion: The prize treatment induces a significantly higher number of contributions from outgoing subjects. However, data indicate that this re-

period of play. Also, when looking at voting behavior in post-defection parts of the game we completely disregard patterns in period 4 since any level here is consistent with both the gift-exchange and the efficiency-concerns hypotheses: A voting decision in this situation is not only costless, it is also haphazard since subjects are completely disenfranchized (the outcome of no prize assured by the automatons inevitable exercise of its veto powers).

${ }^{25}$ Departing from our analytic choice of utilizing the group level as our unit of analysis and/or from the sounder practice of applying within-unit tests (WSR) where this is feasible, we also note that the listed diæerence of $0.80-0.63=0.17$ in vote share averages between the two situations is not signi.cant in the more lenient MWU test between groups $(\mathrm{Z}=-0.63,=0.53$, $\mathrm{N}=7$ ) nor in an MWU test with individual decisions as units of analysis (diø. $=0.80-0.67=0.13$, $\mathrm{Z}=-0.63, \mathrm{p}=0.53, \mathrm{~N}=26)$. 
sult does not originate from use of trigger strategies. Several statistical tests reveal that behavior differs significantly from what one would expect if trigger strategies were to drive behavior. In the prize treatment the focal-point effect likely explains the observed behavior; in fact, this is the only alternative explanation for which we find statistically significanct evidence. Although there is also some evidence that subjects engage in gift-exchange behavior, the small number of observations in our design makes statistically significant evidence for this proposition infeasible.

\section{Conclusion}

Many scholars consider that lame ducks will continue to service their party only if being incentivized. According to the model motivating our experiment, remaining party representatives can discipline lame ducks by credibly promising them exit prizes (such as attractive retreat positions or other post-office perks) if they do not shirk.

We have examined this proposition experimentally. Novel use of automatons allowed us to sidestep the fundamental problem of mimicking parties with indefinite lives in the lab. In one treatment remaining subjects could award cost-free exit prizes to the lame duck. The other treatment did not permit such prizes. We found, in line with the model prediction, that a significantly higher proportion of outgoing subjects contribute in the prize treatment.

Closer inspection, however, revealed that many outgoing subjects who chose to contribute received a prize irrespective of whether the trigger's punishment path had been activated. While inconsistent with the proposed incentive scheme, this behavioral pattern may be understood in several ways. We have indicated three.

First, the strategic situation generates a gift-exchange relationship. Sheer decency suggests that an outgoing player who contributes should be awarded a prize regardless of play in previous periods. The fact that awarding a prize entails zero cost for remaining players makes this moral imperative particularly compelling. Second, because failure to award a prize would leave money on the table, efficiency concerns imply that a prize should be awarded regardless

of previous play. Finally, the prize treatment makes cooperative behavior a powerful focal point, which might explain the observed behavior.

Our data cast doubt on efficiency concerns as a likely explanation, while not 
allowing us to discriminate between gift-exchange and focal-point effects. The presence of either of these two motives, however, might undermine the credibility of the trigger strategy that supposedly sustains the proposed incentive scheme.

The environment we study is very simple: The structure of the game is public knowledge; legislative (mis)behavior cannot impact on reelection prospects, nor on future job prospects (through reputational concerns); end-game behavior is automated; there is no ambiguity with respect to lame-duck periods; all interaction is anonymous; and rewards and punishments are fully controlled by the majority of the party. Clearly, it bears little resemblance to the environment of real world legislative politics. This, however, is hardly an objection. Our environment was designed to control the impact of such other factors, so as to obtain

a rigorous test of one particular hypothesis about legislative behavior: Are lame ducks disciplined by endogenously determined exit prizes? Our experiment indicates that they are, although in ways inconsistent with the standard theory of rational, self-regarding players. This, in turn, suggests that standard theory may be too restrictive to provide a proper understanding of legislative behavior, and that further experiments could be useful to guide future modelling. If subjects in a simple setup like ours deviate systematically from standard theory, one may also expect legislators operating in vastly more complex environments to deviate.

\section{References}

Alchian, A. and H. Demsetz (1972): Production , Information Costs, and Economic Organization. American Economic Review 62(5):777-95.

Alesina, A. and S. Spear (1988): An Overlapping Generations Model of Electoral Competition. Journal of Public Economics 37 (3):359-79.

Bender, B. and J. Lott (1996): Legislator voting and shirking: A critical review of the literature. Public Choice 87:67-100.

Besley, T. and V. Larcinese (2010): Working or Shirking? Expenses and Attendance in the UK Parliament. Public Choice 146(1):291-317.

Cadsby, B. and M. Frank (1990): Experimental tests of Richardian equivalence. Economic Inquiry 29:645-64.

Charness, G. and M. Rabin (2000): Social Preferences: Simple Tests and 
a New Model. Economics Working Paper 441. Department of Economics andBusiness. Universitat Pompeu Fabra.

Crain, W., D. Leavens and R. Tollison (1986): Final Voting in Legislatures. American Economic Review 76(4): 833-41.

Cremer, J. (1992): Cooperation in Ongoing Organizations. Quarterly Journal of Economics 101:33-49.

Diermeir, D. (1995): Commitment, Deference, and Legislative Institutions. American Political Science Review 89(2): 344-55.

Engelman, D. and M. Strobel (2002): Inequality Aversion, Efficiency, and Maximin Preferences in Simple Distribution Experiments. American Economic Review 94(4):857-69.

Fehr, E. \& U. Fischbacher (2005): The Economics of Strong Reciprocity. In: H. Gintis, S. Bowles, R. Boyd \& E. Fehr (eds.): Moral Sentiments and Material Interests: The foundations of Cooperation in Economic Life. Cambridge Mass.: The MIT-Press.

Fehr, E., S. Gächter and G. Kirchsteiger (2005): Reciprocity as a Contract Enforcement Devise. Econometrica 65:833-60.

Fehr, E., M. Naef and K. Schmidt (2005): The Role of Equality and Efficiency in Social Preferences. CEPR Discussion Paper No. 5368.

Fehr, E., G. Kirchsteiger and A. Reidl (1993): Does Fairness Prevent Market Clearing? Quarterly Journal of Economics 108: 437-59.

Fehr, E., G. Kirchsteiger and A. Reidl (1997): Gift Exchange and Reciprocity in Competitive Experimental Markets. European Economic Review 42:1-34.

Fehr, E., A. Klein and K. Schmidt (2001): Fairness, Incentives and Contractual Incompeteness. Working Paper No. 72, Insitute for Empirical Research in Economics, University of Zurich.

Fehr, E. \& U. Fischbacher (2002): Why Social Preferences Matter - The Impact of Non-selfish Motives on Competition, Cooperation and Incentives. The Economic Journal 112:C1-C33.

Fischbacher, U. (1999): Z-tree. Zurich Toolbox for Readymade Economic Experiments. University of Zurich.

Güth, W., H. Kliemt and A. Ockenfels (2000): Fairness vs Efficiency. An Experimental Study of (Mutual) Gift Giving. Berlin: Humbolt University (unpublished).

Hammond, P. (1975): Charity: Altruism or Cooperative Egoism. In E. Phelps (ed.) Altruism, Morality, and Economic Theory. New York: Sage. 
Hsu, M., C. Anen and S. Quartz (2008): The Right and the Good: Distributive Justice and Neural Encoding of Equity and Efficiency. Science 320:1092-5.

Kandori, M. (1992): Social Norms and Community Enforcement. The Review of Economic Studies 59:63-80.

Kopecký, P. and G. Scherlis (2008): Party patronage in Contemporary Europe. European Review 16(3):355-71.

Krehbiel, K. (1990): Information and Legislative Organization. Ann Arbor: University of Michigan Press.

Lien, J. (2008): A politician who's quitting has already quit. M.Sc. thesis (Political Economy). Norwegian School of Management BI.

Lim S, E. Prescott and S. Sunder (1994): Stationary Solution to the Overlapping Generations Model of Fiat Money: Experimental Evidence. Empirical Economics 19:255-77.

Ledyard, J. (1995): Public goods: A survey of experimental research. In A. Roth \& J. Kagel (eds.) Handbook of Experimental Economics. Princeton: Princeton University Press.

Lott, J. (1990): Attendance Rates, Political Shirking, and the Effect of PostElective Office Employment. Economic Inquiry 28:133-50.

Marimon, R. and S. Sunder (1993): Indeterminacy of Equilibria in a Hyperinflationary World: Experimental Evidence. Econometrica 61:1073-1107.

Mutho, A. and K. Shepsle (2007): Information, Institutions and Constitutional Arrangements. University of Harvard (unpublished).

Mutho, A. and K. Shepsle (2004): Agenda-setting power in organizations with overlapping generation of players. University of Harvard (unpublished).

Offerman, T. and H. Verbon (2001): Cooperation in an Overlapping Generations Experiment. Games and Economic Behavior 36:264-75.

Pappas, T. (2009): Patrons Against Partisans: The Politics of Patronage in Mass Ideological Parties. Party Politics 15:315-34.

Parker, G. and S. Powers (2002): Searching for symptoms of political shirking: Congressional Foreign Travel. Public Choice 110: 173-91.

Parker, G. (2004): Self Policing in Politics. Princeton, Princeton University Press.

Rothenberg, L. and M. Sanders (2000): Serving the Electoral Connection: Shirking in the Contemporary Congress. American Journal of Political Science 44(2): 310-19.

Salant, D. (1991): A Repeated Game with Finitely Lived Overlapping Generations of Players. Games and Economic Behavior 3:244-59. 
Shepsle, K. (1986): Institutional Equilibrium and Equilibrium Institutions. In: H. Weisberg (ed.) Political Science: The Science of Politics. New York: Agathon.

Shepsle, K., E. Dickson and R. Houweling (2002): Bargaining in Legislatures with Overlapping Generations of Politicians. Harvard University (unpublished)

Shepsle, K. and B. Nalebuff (1990): The Commitment to Seniority in SelfGoverning Groups. Journal of Law, Economics and Organization 6:45-72

Schelling, T. (1960): The Strategy of Conflict. Cambridge Mass.: Harvard University Press.

Van der Heijden, E., J. Nelissen, J. Potters and H. Verbon (1998): Transfers and the effect of monitoring in an overlapping-generations experiment. European Economic Review 42:1363-91. 


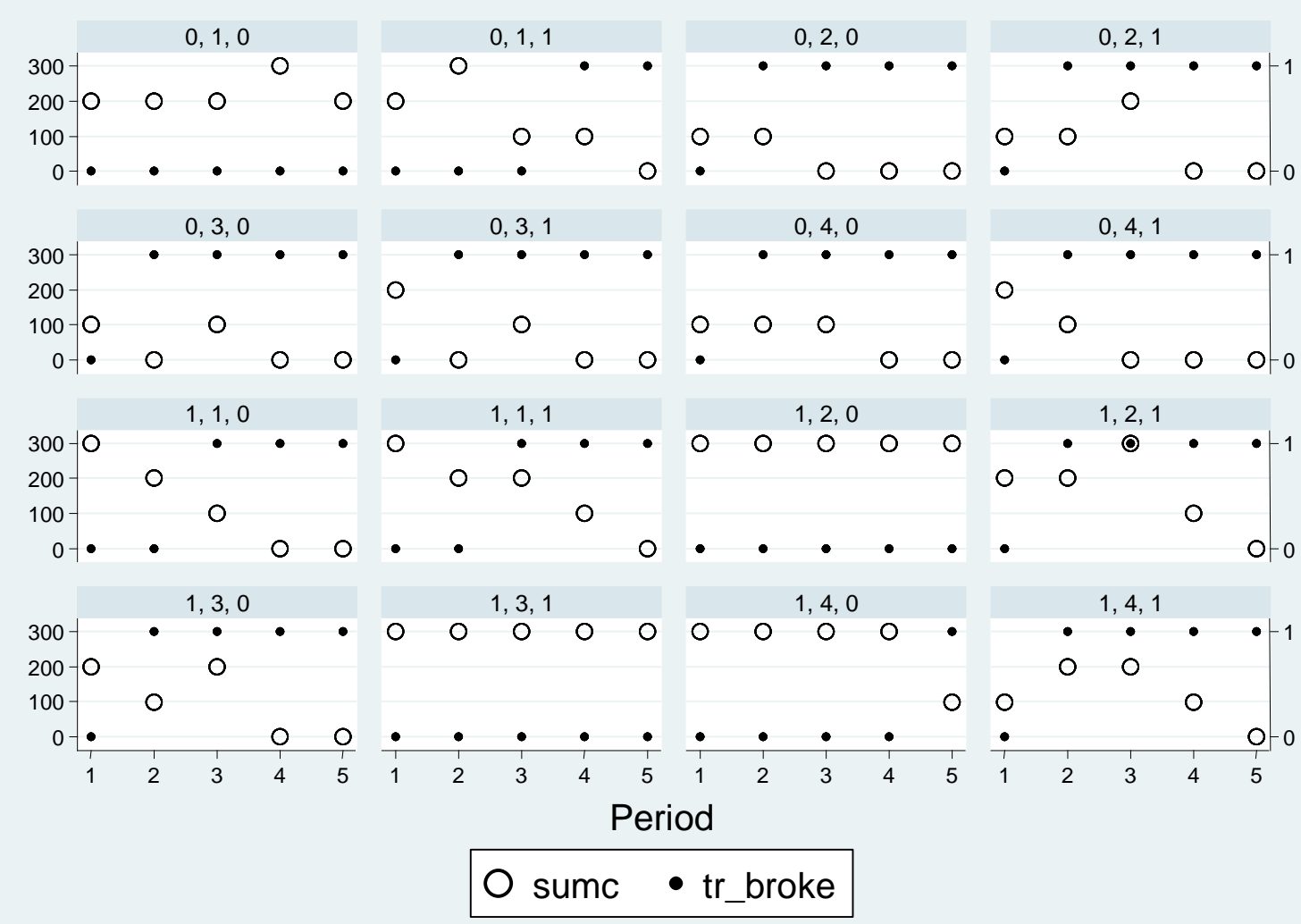

Graphs by contract, group, and day

Figure 1: Total group contributions (hollow circles, left $y$-axis) and whether trigger is broken or not (right $y$-axis, black dots) over periods, contingent on contract availability ( $0=$ No prize, $1=$ Prize), group $(1-4)$, and day (0=First day, $1=$ Second day). 